\title{
Value Conservatism and Its Challenge to Consequentialism
}

\author{
Reuben Sass \\ Rice University
}

***Please only cite official version published in Utilitas 33 (3):337-352 (2021)

\begin{abstract}
G.A. Cohen's value conservatism entails that we ought to preserve some existing sources of value in lieu of more valuable replacements, thereby repudiating maximizing consequentialism. Cohen motivates value conservatism through illustrative cases. The consequentialist, however, can explain many value conservative intuitions by taking extrinsic properties, such as historical significance, to be sources of final value. Nevertheless, it may be intuitive that there's stronger reason to preserve than to promote certain sources of value, especially historically significant things. This motivates an argument that the weights of our reasons to preserve such things are especially strong relative to the amounts of value borne. The value conservative can further explain these intuitions in non-consequentialist terms. There may be reason to preserve historically significant things as a matter of recognition respect for a cultural and historical heritage, or because it is virtuous to cultivate the right kind of connection with such a heritage.
\end{abstract}

\section{Value Conservatism: The Very Idea}

Contemporary philosophy has paid relatively little attention to our reasons for preserving existing sources of value. Yet there are many things which we seem to value in large part because of their place in our history or culture. Among such things are not only historic buildings and works of art, but also institutions and social traditions. We may value such things even if there are few instrumental goods we can attribute to them, and even if there are more valuable and more expedient replacements available. 
G.A. Cohen ${ }^{1}$ takes note of this phenomenon in putting forward a theory of value conservatism. Value conservatism is about what we have reason to value and why we have reason to value it. To wit:

Even if it is worth keeping something only if it satisfies some purpose or principle, it does not follow that the weight of the reason for keeping it is limited to the extent to which it satisfies that purpose or principle...I claim that we devalue the valuable things we have if we keep them only so long as nothing even slightly more valuable comes along. $^{2}$

Cohen's conception of value conservatism entails, at a minimum, that we have reason to preserve some existing sources of value even in lieu of possible replacements that add more total value (whether instrumental or final) than the existing sources. As a result, Cohen explains, "Value-maximizing consequentialism stands in especially sharp contrast with conservatism as I have defined it." ${ }^{3}$ By "maximizing consequentialism," we can understand something like:

Minimal Maximizing Consequentialism: An action is morally permissible if and only if "no alternative in the given choice situation" has consequences which yield more total value. $^{4}$

This coarse-grained conception of maximizing consequentialism will be adequate until section 5. (The maximizing consequentialism at issue isn't concerned with a particular type of value, such as well-being, but value in general).

\footnotetext{
${ }^{1}$ G.A. Cohen, Finding Oneself in the Other ed. by Michael Otsuka (Princeton, 2013), pp. 143-175.

${ }^{2}$ Cohen, p. 153.

${ }^{3}$ Cohen, p. 155.

${ }^{4}$ Peter Vallentyne, Against Maximizing Act Consequentialism, Contemporary Debates in Moral Theory ed. by James Dreier (Wiley-Blackwell, 2006), p. 21.
} 
In section 3, I explain how the maximizing consequentialist can accommodate at least some of the cases motivating value conservatism. For the value conservative, then, it's not enough to merely come up with cases in which it's intuitive that we ought to preserve existing sources of value. For we can allow that many existing sources of value are in fact more valuable than their possible replacements, if we allow that historical significance and rarity can add to final value in certain cases. ${ }^{5}$

The value conservative thus needs a principled way of explaining which things are worth preserving, and why they are worth preserving even at the expense of forgoing more valuable replacements. To make the case, sections 4-6 argue that there's sometimes stronger reason to preserve than to promote certain sources of value, especially historically significant things. Examples at the end of section 5 aim to make this claim intuitive. Accordingly, the weights of our reasons to preserve certain things may be disproportionately strong relative to the amounts of value they bear. If so, we'd sometimes have stronger reason to preserve the less valuable thing in lieu of a more valuable replacement. In sections 6 and 7,1 argue that deontology and virtue theory offer plausible explanations of value conservative intuitions. At the end of sections 5 and 6, I discuss some options and challenges for accommodating such intuitions within a consequentialist framework. But I conclude by drawing out the nonconsequentialist story.

\section{Formulating the Value Conservative Thesis}

Now there are multiple possible formulations of value conservatism, and it isn't immediately obvious which formulations are both defensible and interesting. In this section I

\footnotetext{
${ }^{5}$ Shelly Kagan, Rethinking Intrinsic Value, The Journal of Ethics 2.4 (1998), 277-297; Christine M. Korsgaard, Two Distinctions in Goodness, The Philosophical Review 92.2 (1983), 169-195.
} 
work towards a preliminary formulation of value conservatism, for which I then present a challenge in the following section.

One challenge to value conservatism concerns the scope of the claim the value conservative wants to make. I doubt the value conservative wants to make a universally quantified deontic claim - that all sources of existing value ought to be preserved from all possible replacements of greater value. Even the most extreme reactionary would be hardpressed to make this claim. As Cohen himself notes: "The conservative propensity is to conserve, to not destroy, and therefore to not replace, even (within limits) by something more valuable. ${ }^{6}$ Yet what is the scope of these limits to which Cohen refers? It doesn't make sense to conserve that which is of merely instrumental value in lieu of replacements with greater instrumental value.

Value conservatism may well be limited to things that have final value, or the value that something has for its own sake, independent of the consequences of its existence. (I do not limit final value to the value something has solely in virtue of its intrinsic properties). Even so, it is implausible that we ought to preserve all sources of final value from all possible replacements. Consider, for example, an artist who destroys one painting as part of the process of creating a better one. Or consider a country's constitution (as a type rather than a token), which arguably has some final value aside from its instrumental value in promoting good government. A constitution may have final value insofar as it embodies a nation's ideals, but that doesn't mean it may not make sense to replace a constitution in response to changing times.

\footnotetext{
${ }^{6}$ Cohen, p. 156.
} 
In any case, given Cohen's acknowledgement that there are limits to preserving existing sources of final value, the value conservative would likely have to make an existentially quantified claim such as the following:

Minimal Value Conservatism (MVC): There are some existing sources of value that ought to be preserved even from possible replacements of greater value.

Much of the dialectical interest of MVC would lie in MVC's rejection of maximizing consequentialism. But it is questionable whether MVC is fine-grained enough to target what is of interest to the value conservative. Indeed, there is nothing in MVC about which existing sources of value ought to be preserved from possible replacements of greater value. Presumably there is some principled way of delimiting the sorts of things to which the value conservative thesis would apply. Without such a principle, it could be an unexplained or random occurrence that a thing ought to be preserved even in lieu of more valuable replacements.

Now the value conservative is interested, in particular, in explaining why we ought to preserve existing institutions and social traditions over more valuable replacements, as well as why we ought to preserve certain physical artifacts such as buildings and works of art. Yet it is not as if the value conservative would want to claim that all existing institutions and traditions ought to be preserved in lieu of more valuable replacements, or that there are no circumstances in which we ought to demolish a historic building in favor of a much more useful modern one.

The value conservative might draw on cases in which existing sources of value have some combination of rarity, historical significance, and resistance to replacement. But the notion of resistance to replacement can be construed in many ways which are not morally 
meaningful, as Hatala-Matthes explains. ${ }^{7}$ Perhaps, then, the objects to which value conservative intuitions apply are those that put us in touch with the past. ${ }^{8}$ But I think it is not the past simpliciter with which we should want to be put in touch. For as Hatala-Matthes also notes, any object can be traced back through a causal chain connected with past events.

Thus I would prefer to speak of things which put us in touch with a cultural and historical heritage (to borrow another of Hatala-Matthes's terms) ${ }^{9}$ encompassing various events, traditions, people, and ideals. Under some duress, I refer to things which can so put us in touch as "historically significant things." In my usage, historically significant things are limited to what we have broadly shared, and perhaps even universal, reasons to consider important or necessary to preserve. Accordingly, the examples of historically significant things I discuss include great paintings, constitutions, historic buildings and neighborhoods, memorials, community traditions and institutions (perhaps even Cohen's own Oxford college of All Souls).

I won't try to analyze either the relation of being "put in touch," or the notion of a cultural and historical heritage. I think we can get an adequate grip on these notions through illustrative cases. But I do think, following Hatala-Matthes and Korsmeyer, ${ }^{10}$ that there needs to be some close spatiotemporal or causal connection between a historically significant thing and what the thing puts us in touch with. The Guernica puts us in touch with Picasso's genius, and perhaps with the Spanish Civil War, in a way that a reproduction does not.

I argue, then, that the value conservative should focus on our reasons to preserve things which put us in touch with a cultural and historical heritage. Rarity and resistance to replacement are secondary considerations, although they may make a historically and culturally significant thing more worthy of preservation.

\footnotetext{
${ }^{7}$ Erich Hatala Matthes, History, Value, and Irreplaceability, Ethics 124.1 (2013), 35-64.

${ }^{8}$ Hatala Matthes (2013), 60-64.

${ }^{9}$ Erich Hatala Matthes, Impersonal value, Universal Value, and the Scope of Cultural Heritage, Ethics 125.4 (2015), 999-1027.

${ }^{10}$ Carolyn Korsmeyer, Things: In touch With the Past (Oxford, 2019).
} 
In any case, the value conservative can claim:

Proper Value Conservatism (PVC): There are some things whose status as historically significant provides sufficient reason to preserve them, even when somewhat more valuable replacements are available.

The putative evidence for PVC would stem from our intuitive judgments about cases in which we would be inclined to preserve historically significant things over possible replacements. One could of course dispute such intuitive judgments, though I will accept that such judgments are indeed correct.

\section{The Consequentialist Challenge}

The central problem for the value conservative is that it isn't clear, in many of the cases which ostensibly motivate PVC, that the replacements are more valuable than what they would be replacing. Perhaps our intuitions in favor of preservation are justified because the existing sources of value have greater value than their replacements. If so, the conservative hasn't mustered any counterexamples against consequentialism.

Indeed, it is consistent with maximizing consequentialism that historical significance often increases a thing's final value. Great works of art and historical artifacts such as the pen that Lincoln used to sign the Emancipation Proclamation ${ }^{11}$ might plausibly have greater final value in virtue of their relation to certain historical events and cultural moments. At any rate, the maximizing consequentialist can make the case that the value added by historical significance is often enough to justify keeping existing sources of value. The final value of these

\footnotetext{
${ }^{11}$ Kagan, p. 285.
} 
existing sources, combined with certain instrumental benefits, could (in many cases) outweigh the total value added by the possible replacements.

The consequentialist can likewise offer a principled rationale for when we ought to preserve existing sources of value and when we ought to replace them. Namely, we ought to replace an existing thing if and only if doing so will result in greater total value. Thus the consequentialist might claim:

Consequentialist Norms for Preserving Sources of Value (CPV): For any existing source of value $E$, we ought to preserve $E$, in lieu of a possible replacement $R$, only insofar as $E$ as has greater total value (final and instrumental) than $\mathrm{R}$.

The value conservative will of course claim that CPV is exactly what the conservative seeks to deny. But the consequentialist will claim that the value conservative's rejection of CPV is not well-motivated, since many cases that the value conservative appeals to do not require us to reject CPV. If maximizing consequentialism is otherwise well-motivated, then we ought not reject it unless we can support such a rejection.

Consider Cohen's example of All Souls and its (rather insular) traditions. Cohen maintains that All Souls would be justified in rejecting at least some updates to its traditions, even if such updates would bring All Souls into alignment with the standards of modern research universities. But we might plausibly take the All Souls traditions to have final value themselves, and moreover to produce instrumental value by promoting morale and esprit de corps among the college's members. The upshot is that even if we want to say that All Souls should resist replacing some of its old-fashioned standards and traditions, we need not thereby commit to rejecting maximizing consequentialism. For it might turn out, given the historical significance and morale-boosting effects of certain traditions, that replacing those traditions might actually result in lower total value than keeping those traditions. 
Drawing on such examples, the consequentialist can say that we will often have good reason to keep many of the existing sources of value that the value conservative claims she wants to preserve. It just happens that we can account for our reason to keep these existing sources of value by appealing to the fact that they often have greater total value than their replacements. To be precise:

\section{Consequentialist Rationale for Preserving Existing Sources of Value (CRV): There are} some existing sources of value $E_{0} \ldots E_{n}$, such that for any $E_{i}$ in $E_{0} \ldots E_{n}, E_{i}$ has greater total value than most or all of its viable possible replacements $R_{0} \ldots R_{n}$. In many of the cases to which the value conservative appeals, $E_{i}^{\prime}$ s having greater value than most or all of $R_{0} \ldots R_{n}$ will be attributable to $E_{i}$ 's having some combination of historical significance, rarity, or difficulty or impossibility of replacement.

The consequentialist can further challenge the value conservative to come up with a principled test for when existing sources of value should be replaced and when they shouldn't. Indeed, the consequentialist can use a principle such as CPV as such a principled test. But what test can the value conservative use? The value conservative is not committed to rejecting the replacement of all existing sources of value. So clearly there are some cases in which even the value conservative admits we ought to replace an existing source of value. And, if value conservatism is to be a defensible theory in normative ethics, it should be able to offer some principled norms for how to deal with such cases.

Perhaps a historic building is very valuable in virtue of both its aesthetic value and its historical significance. Now suppose that the historic building presents a serious safety and fire hazard. The question might arise: Is it worth preserving the building and paying extremely high repair costs, when a modern replacement would be cheaper and more commodious? The consequentialist, in accepting CPV and CRV, can propose a simple test: Add together the final 
value of the original building (grounded in historical significance, rarity, aesthetic virtues, etc) and its instrumental value (grounded in pleasure and knowledge gains for tourists, for example). If both the final and instrumental value of the original outweigh the final and instrumental value of the replacement building, keep the original building. Otherwise, replace the original. This does not seem like an implausible approach. And more importantly, it captures, in a way consistent with maximizing consequentialism, the intuition that there is some value in the original building, but that that value is not infinite and can be outweighed.

Likewise, a constitution may have both final and instrumental value. A constitution may have final value insofar as it embodies the historical traditions and values of a people, and it may have instrumental value insofar as it promotes good government and prosperity. But clearly there are times when a constitution should be replaced or substantially revised, particularly if the constitution is no longer promoting good government and prosperity. And the maximizing consequentialist can plausibly say that such cases occur when the total (final and instrumental) value of the original constitution is outweighed by the total value of the replacement.

Now the value conservative might herself appeal to historical significance, or aesthetic merit, or rarity, to explain why an original should be preferred over potential replacements. Perhaps we only ought to preserve that which is historically significant enough, or beautiful enough, to warrant preservation in the face of more instrumentally valuable replacements. But this sounds a lot like what the maximizing consequentialist would say, at least assuming we allow historical significance to be a source of final value. And the consequentialist who accepts CPV and CRV would be perfectly happy to allow historical significance to add final value. Indeed, if the value conservative resorts to a balancing of different values, then it seems plausible to consider whether the value attributable to the replacement outweighs the value attributable to the original. 
Perhaps it's just a brute fact that we ought to preserve certain historically significant things in lieu of some more valuable replacements. But what reason would we have to accept such brute facts, especially in light of the consequentialist's case? At the very least, the resort to such brute moral facts seems ad hoc and arguably question-begging against the consequentialist. For the consequentialist is asking for an explanation of why we ought to preserve rare and historically significant things, even at the expense of value-maximization. And the mere fact that one ought to do so seems more like the explanandum than the explanans. Perhaps the consequentialist is getting it wrong, but a deeper explanatory story would at least seem to be dialectically advantageous against consequentialist concerns.

Accordingly, the value conservative needs to offer a principled reason to reject maximizing consequentialism. In particular, the value conservative needs to explain the inadequacy of the consequentialist's justification for keeping existing sources of value-namely, that the things the conservative wants to preserve may have greater total value than their replacements, after factoring in the value of historical significance, aesthetic significance, and associated instrumental benefits. In so doing, the value conservative might provide an interesting positive account of what could ground the truth of PVC.

\section{Sharpening the Consequentialist Challenge}

We could, of course, stipulate that the historically significant things in Cohen-style cases have equal or lesser value than their possible replacements. Consider another case: OLD/NEW BUILDING. Suppose the value of OLD BUILDING is grounded in OLD BUILDING's historically, aesthetically and culturally significant features. And suppose the value of NEW BUILDING is grounded in NEW BUILDING's convenience as an office space and the productivity this enables. The value conservative wants to say there could be stronger reason to preserve OLD BUILDING than to replace it with NEW BUILDING, even if the two are of equal value (accounting for all costs and benefits). Perhaps, that is, OLD BUILDING's historically significant features give us stronger 
reason to preserve OLD BUILDING than features of equal value grounded in NEW BUILDING's convenience as an office space. Wouldn't it seem fitting, after all, to feel more regret at destroying OLD BUILDING than at forgoing the opportunity to build NEW BUILDING? The consequentialist, however, would have to say that there's equally strong reason to preserve or replace OLD BUILDING, so long as OLD BUILDING and NEW each have equal value.

But if there were stronger reason to preserve OLD BUILDING than to replace it with NEW when the two are of equal value, couldn't this still be the case if NEW BUILDING were of slightly greater value than OLD BUILDING? Suppose NEW BUILDING is more valuable than OLD BUILDING by .1 units, or .01 units, or .001 units of value. Especially if NEW BUILDING were only very slightly more valuable than OLD BUILDING, it might seem intuitive that our reasons to preserve OLD BUILDING - reasons stemming from OLD BUILDING's historical significance-could, contrary to consequentialism, outweigh the reasons to replace it with NEW BUILDING. So the weights of reasons to preserve things might depend not only on the amount of value they bear, but also on the type of value they bear-e.g. value grounded in historical significance versus value grounded in utility-promotion.

But there's a problem. For the consequentialist can say that despite our stipulating that OLD BUILDING is less valuable, what the intuiter is really intuiting is that OLD BUILDING is more valuable, given our ordinary concept of value.

Consider a simple consequentialist account of the relation between value and the weights of reasons:

Normative Value-Maximizing Consequentialism (NVMC): (1) The weight of a normative reason $\mathrm{R}$ to $\phi$ or not $\phi$ is perfectly correlated with, and explained by, the amount of value $^{12}$ that would be gained or lost, respectively, in virtue of $R$. And (2): $R$ is a

\footnotetext{
${ }^{12}$ For subjective consequentialism, amounts of value might be multiplied by expected probabilities (from $0-1$ ) to compute the weight of reasons. See Barry Maguire, The Value-Based Theory of Reasons, Ergo 3.9 (2016), 243.
} 
normative reason to $\phi$ or not $\phi$ iff $\mathrm{R}$ is a benefit or cost, respectively, of $\phi$-ing. A benefit of an action is a consequence of an action that yields an increase in total value, and a cost of an action is a consequence of an action that yields a decrease in total value.

Now it's (likely) not a conceptual truth that the strength of a reason to preserve or promote something is directly correlated with the amount of value it bears. Might not the type of value-historical significance versus utility, for example-also affect the weight of such a reason, in addition to the amount of value? But NVMC has the advantage both of parsimony and of prima facie plausibility. The burden might well lie on the value conservative to refute it. ${ }^{13}$ The value conservative attempts to do so through cases like OLD/NEW BUILDING.

Nevertheless, the consequentialist can claim that NVMC (given its plausibility and parsimony) tracks our ordinary concept of value. If so, then despite any stipulations to the contrary, the ordinary intuiter might only be intuiting that we ought to preserve a historically significant thing because she's also intuiting that we ought to think that thing is more valuable than its replacement.

\section{The Value Conservative Response}

In response, the value conservative may pursue two strategies: (1) adding further details to cases like OLD/NEW BUILDING, to illustrate that the replacement really is more valuable than the original, and (2) claiming that we sometimes have stronger reason to preserve certain things than to create or promote them. Indeed, value conservatism is about preservation-its basic thesis is that we sometimes have stronger reason to preserve the less valuable thing. So here I focus on (2). But at the end of this section, I offer cases to defend (2) which also address (1).

\footnotetext{
${ }^{13} \mathrm{~A}$ similar point was raised by the editor in correspondence.
} 
Now if NVMC is right, then the weight of a reason to preserve something should be equal to the weight of the reason to promote it, so long as its value remains the same. The value conservative may argue, instead, that our reasons to promote and preserve value can be asymmetric in the following respect:

Preserving Existing Value (PEV): There are some things $x_{0} \ldots x_{n}$, such that our reasons to preserve $\mathrm{x}_{0} \ldots \mathrm{x}_{\mathrm{n}}$, given that $\mathrm{x}_{0} \ldots \mathrm{x}_{\mathrm{n}}$ already exist, may be stronger than our reasons to promote the existence of $\mathrm{x}_{0} \ldots \mathrm{x}_{\mathrm{n}}$ (in a world exactly similar to ours except lacking $\mathrm{x}_{0} \ldots \mathrm{x}_{\mathrm{n}}$ ), or to promote the existence of some things $y_{0} \ldots y_{n}$ with all the value-conferring properties of $x_{0} \ldots x_{n}$

Of course, it might seem a bit paradoxical to say we sometimes have stronger reason to promote the less valuable thing. The paradox might be reinforced if we set aside partiality, and say that there can be stronger agent-neutral reason to promote the less valuable thing. Given PEV, however, the value conservative does not have to say this. Rather, the value conservative need only say that we sometimes have stronger reason to preserve the less valuable thing. Indeed, if there's sometimes an asymmetry between the weights of our reasons to promote and to preserve, then there could sometimes be sufficient reason to preserve $\mathrm{x}$ in lieu of y even if there wouldn't be sufficient reason to promote $\mathrm{x}$ instead of $\mathrm{y}$. That is, the following pattern could hold:

Weight of the reason to preserve $\mathrm{x}=98$

Weight of the reason to promote $\mathrm{x}=90$

Weight of the reason to promote $\mathrm{y}=95$

Weight the reason to preserve $\mathrm{y}=95$ 
What matters here is the general pattern. The margins between the weights of reasons can be increased or decreased depending on the case. Later I discuss some cases which exemplify the pattern.

Suppose a thing's amount of value is either (1) directly correlated with the weight of the reason to promote it, or (2) correlated with the average of the weights of the reasons to promote and to preserve it. (That's not to assume that reasons have explanatory priority over value; it's sufficient here to posit mere correlation). ${ }^{14}$ Take the pattern above. If (1) is true, then $y$ would be more valuable than $x$ by the equivalent of 5 units; if (2) is true, then y would be more valuable than $\mathrm{x}$ by the equivalent of 1 unit. But if the pattern holds, there's still stronger reason to preserve $\mathrm{x}$ rather than $\mathrm{y}$. So there would be stronger reason to preserve the less valuable thing. And value conservatism would be true, since it's an existentially quantified claim.

Consequentialists, of course, might want to assimilate preservation to promotion, and deny PEV. But if PEV is true, it's plausible that amounts of value would either track the weights of our reasons to promote, our reasons to preserve, or a (possibly weighted) average of these types of reasons. Of course, if value were only correlated with our reasons to preserve, then even patterns such as the one above wouldn't vindicate value conservatism. For it would then be sufficient for $\mathrm{x}$ to be more valuable than $\mathrm{y}$ for there to be stronger reason to preserve $\mathrm{x}$ rather than $\mathrm{y}$, even if there were stronger reason to promote $\mathrm{y}$ rather than $\mathrm{x}$. But it seems highly unintuitive that value would track only the weights of our reasons to preserve rather than to promote. Value-maximizing consequentialism, for example, typically focuses on the promotion relation - what it is desirable to bring into existence. That may be why utilitarianism is the archetypal form of consequentialism, even if it is no longer the most widely accepted.

\footnotetext{
${ }^{14}$ See Thomas Scanlon, What We Owe to Each Other (Belknap, 1998), pp. 78-108.
} 
In any case, PEV may not only help value conservatism avoid paradox. It may also bring the nature of value conservatism into sharper relief. For value conservative intuitions needn't be limited to historically significant things. Value conservatism is more generally about our especially strong reasons to preserve certain kinds of things that already exist, and have existed for some time.

Indeed, philosophy of love ${ }^{15}$ also presents us with cases in which we can choose between an existing loved one and a possible replacement who is the same as the original except more perfect in every respect. We're supposed to intuit that it would be perverse to accept the replacement, even though the replacement loved one adds more value than the original. Likewise, it seems intuitive that our reason to preserve a child is stronger than our reason to create a new one, even if the new child were to be more perfect in every attribute, and even if we were guaranteed to love the new child as much or more than the old one.

But such cases often reflect agent-relative reasons, and so may be caught up in challenges to consequentialism based on partiality. Love is a paradigmatic case of agentrelative reasons: those whom we love are loved by few others, and others have less reason to care about them than we do. ${ }^{16}$ That's not to deny the importance of partiality-far from it. But I don't think the value conservative challenge is exhausted by the agent-relativity of reasons. Thus I want to focus on things which we have broadly shared, and perhaps even agent-neutral, reasons to preserve. Certain historically significant things seem to fit the bill (see section 2). Of course, one might have stronger reason to care about what is historically significant for one's own society than for another. But we may still have some agent-neutral reason to care whether other societies can preserve what is of greatest historical significance to them. ${ }^{17}$

\footnotetext{
${ }^{15}$ Robert Kraut, Love de re, Midwest Studies in Philosophy 10 (1986), 413-430; Christopher Grau, Irreplaceability and Unique Value, Philosophical Topics 32.1/2 (2004), 111-129.

${ }^{16}$ See Barry Maguire, Love in the Time of Consequentialism, Noûs 51.4 (2017), 686-712.

17 There's an interesting question about which factors influence the weight of our reasons to preserve historically significant things. Something's degree of historical significance may correlate somewhat with the strength of
} 
Consider the following: CATHEDRAL/THEME PARK. Suppose there's a choice between preserving an existing cathedral or replacing it with a new theme park. We might intuit that there's stronger (agent-neutral) reason to preserve CATHEDRAL than to replace it with THEME PARK. Indeed, we might be able to point to particular features of historical, cultural and aesthetic significance which the cathedral has that we would have reason to regret losing-the artwork in the stained glass windows, or the fact that the cathedral "puts in touch" with some historical event or era. But it's also intuitive that there would be reason to regret not building THEME PARK. Perhaps THEME PARK adds a great deal of economic activity, and has many fun rides for the children. And perhaps there is a lack of fun activities for children in the town, outside of video games. Nevertheless, given CATHEDRAL's place in our cultural and historical heritage, we may intuit that our reason to regret its loss-and to preserve it so as to avoid that loss-would justify the opportunity costs of forgoing a new source of entertainment in town.

Now suppose we have to choose between creating a cathedral (FUTURE CATHEDRAL) versus creating THEME PARK. Suppose that FUTURE CATHEDRAL is very similar to CATHEDRAL in its determinate properties, and that FUTURE CATHEDRAL would acquire the same kind of historical significance as CATHEDRAL. Suppose further that, because of extremely tedious building permits and zoning regulations on theme parks, the time at which THEME PARK would become operational is the same time at which FUTURE CATHEDRAL would acquire the same kind of historical significance as the original CATHEDRAL.

\footnotetext{
agent-neutral reasons to preserve it: the Pyramids were built by a long-gone civilization, but are very historically significant. It would likely be widely regarded as a great tragedy if the Pyramids were destroyed. But relevance to the lives and practices of current cultures might also strengthen our reasons to preserve things. Consider sacred burial sites; we might have stronger reason to preserve such sites out of respect for a current indigenous culture than one that has long since passed. The weight of our reasons to preserve such sites might in turn determine whether it's permissible to redevelop certain lands, or whether certain artifacts ought to remain in place instead of being relocated. On the other hand, ancient artifacts may be more historically significant because they are so old, even if they are less relevant to current cultural practices. These are important questions of ethics and policy, but I can't explore them further here.
} 
Even so, mightn't it seem plausible that there could be stronger reason to preserve CATHEDRAL than to create FUTURE CATHEDRAL? Indeed, CATHEDRAL is part of an existing cultural heritage. Perhaps by failing to preserve CATHEDRAL we would in some sense be disrespecting such a heritage. (See the following section). But this consideration couldn't count in favor of building FUTURE CATHEDRAL, since FUTURE CATHEDRAL is not (yet) part of an existing cultural heritage. So perhaps it could seem fitting to keep CATHEDRAL given that CATHEDRAL already exists, but build THEME PARK instead of FUTURE CATHEDRAL in the world where the original CATHEDRAL doesn't exist.

The intuition might be made starker if the question is whether to replace MEMORIAL with THEME PARK, where MEMORIAL is a memorial to a war of some importance. It might seem that tearing down MEMORIAL to build THEME PARK is an act of gross disrespect to our cultural heritage, and to the sacrifices given by the war dead. At the same time, if the choice were instead whether to build MEMORIAL or THEME PARK, the calculus could be different. If THEME PARK were valuable enough, given all the tax revenue it produces and the fun it offers for the town's kids, then perhaps building THEME PARK should be prioritized over building MEMORIAL. Perhaps, then, a much smaller memorial might be considered adequate.

The simplest response for the consequentialist is to reject the intuitions that the value conservative seeks to elicit in cases like MEMORIAL/THEME PARK and CATHEDRAL/FUTURE CATHEDRAL/THEME PARK. But insofar as such intuitions are plausible, this may be a theoretical cost for the consequentialist. If the consequentialist doesn't want to reject the intuitions, she may say that existence adds value. So we'd have stronger reason to preserve something than to promote a possible equivalent, but only because the possible equivalent is missing a feature which makes the existing thing valuable: namely, existence. ${ }^{18}$ But this is an odd thing to say, given that existence is not typically taken to be a property. How then could existence ground

\footnotetext{
${ }^{18}$ Geoffrey Brennan and Alan Hamlin, Conservative Value, The Monist 99.4 (2016), 352-371.
} 
value? Perhaps the fact that something has existed can add value to it. But in many cases, the strength of the reason to preserve a thing is the same as the strength of the reason to promote or create it. In such cases it wouldn't make sense to say that something is more valuable because it has existed. Consider more fungible sources of value, such as states of happiness, or utility-promoting things like theme parks or movie theaters. For these things it seems as if the mere fact of previous existence (rather than utility-promotion) adds no value. So why would existence add value only in some cases, like historical significance?

\section{Explaining the Value Conservative Response}

The value conservative can avoid similar puzzles by drawing on non-consequentialist explanations of PEV. In cases like MEMORIAL/THEME PARK, it's supposed to be intuitive that historically significant things merit a certain respect. The kind of respect at issue is recognition respect. Recognition respect is canonically focused on persons, but in Darwall's ${ }^{19}$ original conception of it, it need not be limited to persons. Recognition respect is about assigning a certain weight to a certain class of things in one's deliberations about what to do with regard to things of that class. More succinctly, recognition respect is about giving things their due.

Perhaps there's a (defeasible) duty to show recognition respect for a cultural and historical heritage. Indeed, we are all in some way connected with a cultural and historical heritage, no matter how isolated we may be. Plausibly, some respect ought to be given to such a heritage, especially if that heritage is itself involved in the constitution of our social and cultural identities and self-understanding. Hatala-Matthes, ${ }^{20}$ indeed, refers to there being broadly shared reasons to preserve or respect a cultural heritage, which historically significant things would put us in touch with.

\footnotetext{
${ }^{19}$ Stephen Darwall, Two kinds of Respect, Ethics 88.1 (1977), 36-49.

${ }^{20}$ Hatala Matthes (2015), 1016-1022.
} 
One important way to show recognition respect for a cultural heritage would be to preserve and desire to preserve the things which put us in touch with that heritage. (Indeed, I take this relation of "putting us in touch" as the mark of historically significant things [see section 2]). For such a heritage would be sustained through the existence of historically significant things. By preserving such things we would be indicating that we take that heritage seriously. To not preserve such things may then be to show disrespect for that heritage. And the avoidance of disrespect may be the subject of a strong imperative-more so even than actively showing respect. That was the intuition being plumbed in MEMORIAL/THEME PARK.

Likewise, I doubt a cultural heritage is best respected simply by adding more things purported to be connected with that heritage. More plausibly, such a heritage is best respected by carefully preserving and curating those things which put us in touch with it. Sometimes it may be wise to add things which will acquire historical significance. But the value conservative, at least, intuits that this ought to be done without needlessly disrespecting an existing heritage.

Of course, recognition respect for a cultural and historical heritage also involves acknowledging past tragedies and mistakes. Preserving things which put us in touch with such tragedies is necessary for maintaining our heritage in the right way, by indicating which aspects of our history we ought to avoid repeating. One might think here of memorials and museums devoted to the Holocaust and the Rwandan genocide. Such memorials, as a way of respecting what was lost, are among the most important aspects of our cultural heritage.

Now there's another non-consequentialist explanation of PEV, one drawing on virtue theory. The virtue-theoretic explanation may fasten on the cultivation of a connection with a cultural heritage as being a kind of virtue for a social individual. Indeed, on the virtue-theoretic 
notion of an individual, ${ }^{21}$ there would be multiple factors along which the goodness of that individual's life could be assessed. Connectedness with a cultural heritage might encompass a variety of other virtues, such as social awareness, charitableness, and perhaps even respectfulness. Regardless, such an approach would consider it important and perhaps essential for a good life that such connectedness be developed, independently of any imperative to maximize total value. (And not just any form of connection will do. The virtuous individual would need to discriminate between those aspects of a cultural heritage which ought to be preserved as a cautionary tale, and those which ought to be preserved as worthy of emulation).

Consider a person who lives in a society that has historic buildings, museums, academic institutions, local traditions, etc. But now suppose this person does not take advantage of or care about opportunities for engaging with any of these. I think we would consider such a person's life to be lacking in an important respect. The explanation of such a lack need not be given in consequentialist terms. It could also be given in terms of the incomplete fulfillment of standards of virtue essential to a good life for a social individual.

Consider also a society in which there were no historic buildings, museums, theaters, public monuments, or communal traditions. Many of us would not want to live in such a society. And even if we could tolerate life in such a society, it's natural to think there would be something lacking or flawed about that society. The virtue theorist might explain this intuition by saying that it is the function or purpose of society to afford opportunities for the development of human capacities and virtues, and as part of that purpose society ought to promote opportunities for cultivating a connection with a cultural heritage. The destruction of

\footnotetext{
${ }^{21}$ See e.g. Alsadair MacIntyre, After Virtue (Bloomsbury, 1981); Richard Kraut, Aristotle on the Human Good (Princeton, 1991).
} 
things which put us in touch with such a heritage deprives us of opportunities for cultivating that connection.

Now perhaps a cultural heritage itself has a value, over and above the value of the historically significant things which sustain it. Perhaps this would allow for a consequentialist explanation of value conservative intuitions, without resorting to error theory about such intuitions. In that case preserving a historically significant thing would not only contribute value insofar as it preserved that thing, but insofar as that thing's existence contributed to a cultural heritage which bore value of its own. That might explain our especially strong reasons to preserve historically significant things.

This, however, would be to reify a cultural heritage as a kind of abstract object that could bear a value distinct from the value of the concrete things which sustain it. That may strike some as metaphysically odd. (The value conservative doesn't have to claim that a heritage has properties such as bearing value). In any case, it's not clear that assigning value to a cultural heritage could capture the important asymmetry between preserving an existing heritage and creating new things which would acquire historical significance. Again, the value conservative seeks to capture this asymmetry in two ways. First, she emphasizes the importance of avoiding disrespect towards historically significant things. Second, she claims a heritage is best respected by carefully preserving and curating historically significant things, rather than creating as many things as possible which might acquire historical significance.

Perhaps these intuitions could be vindicated in a consequentialist framework. But there would be significant challenges. First, simplicity is a virtue of the consequentialist account of the weights of reasons. To complicate the story might be to erode this advantage, and thereby call into question the motivations for a consequentializing explanation. So the consequentialist should probably avoid attributing some distinct type of value to historically significant things, with a different aggregative principle than intrinsic value simpliciter. Instead, the 
consequentialist could try to incorporate recognition respect into a substantive axiology. That is, recognition respect could be taken (like utility) as a source of value. This preserves qualitative parsimony among types of value, though not quantitative parsimony among sources of value. But this requires that it be coherent to talk about promoting recognition respect. Indeed, recognition respect would not be promoted simply by creating as much historically and culturally significant stuff as possible, at least if value conservative intuitions are correct. Accounting for this feature of recognition respect could further complicate a consequentialist story. It would then become more important to clarify what explanatory advantage such a story offers.

\section{The Relevance of Regret}

A respect-centric deontology or virtue theory may likewise explain some related intuitions about our moral psychology. Indeed, our reasons for regret may seem much stronger in cases where historically significant things are being replaced, rather than more fungible sources of value. And this asymmetry cannot be explained by historically significant things being more valuable, on average, than more fungible or utility-promoting sources. For the question is about how much reason we have to regret something's loss, conditional on its being replaced by something very similar but better. Suppose a historically or aesthetically significant thing is replaced by something similar but much better-perhaps something which puts us in touch with a much more important part of our cultural heritage. In that case, we may still have more reason to regret the loss of the original than we do when a more fungible source of utility is replaced by something similar but better. ${ }^{22}$

\footnotetext{
${ }^{22} \mathrm{~A}$ similar idea was suggested by an anonymous reviewer.
} 
Consider a case in which NEW OFFICE requires the destruction of OLD OFFICE. NEW OFFICE is better than OLD, and OLD needed to be destroyed for the creation of NEW. Neither office has much aesthetic merit, cultural or even personal significance. It's just a question of which promotes more productivity. But even if OLD OFFICE had a lot of value (insofar as it promoted a lot of utility), it may seem odd and perhaps even unfitting to feel too much regret over the loss of OLD OFFICE, given that it's being replaced by a better office. Indeed we might have reason to worry about an executive who got too emotional over the loss of an old office. Substantial regret might seem odd even if OLD OFFICE were very similar to NEW OFFICE-even if NEW OFFICE had just a slightly larger workspace and slightly better lighting. Thus it doesn't seem like our relatively weak reason for regret could be explained by OLD OFFICE's having little value, for OLD OFFICE would be only slightly less valuable than NEW, given their very similar features.

Indeed, suppose both NEW and OLD OFFICE are very large workspaces responsible for a tremendous amount of economic activity, tax revenue, and innovation. In that case NEW and OLD OFFICE could both carry a lot of value, in absolute terms. Intuitively, however, this wouldn't seem to greatly affect the strength of our reason to regret the loss of OLD OFFICE, conditional on its being replaced by NEW OFFICE.

Consider, on the other hand, a painter who repaints a painting, adapting the previous painting beyond recognition. Suppose that the new GREAT PAINTING is better than the original GOOD PAINTING - more original, more striking -in most respects. Even though GOOD PAINTING's destruction was necessary for the creation of GREAT PAINTING, and even though GOOD PAINTING's existence was quite transient, it might still seem as if there's a strong reason to regret the loss of GOOD PAINTING. It would be natural for the painter or critic to remark upon certain features of GOOD PAINTING that she regrets having lost or having been unable to duplicate in GREAT PAINTING. Perhaps the art-lover-much less the artist! - might even be 
tempted to cry over the loss of GOOD PAINTING. And yet, despite the new painting being better than the old, it would seem unreasonable-indeed positively nasty-to reproach the art-lover for crying over the loss of GOOD PAINTING. The layperson who knows little of art might still find strong reason to be moved over the loss of GOOD PAINTING, even if she isn't regretful enough to cry over it. Since the layperson would presumably have little agent-relative reason to regret the loss of GOOD PAINTING, and yet still might find it fitting to feel significant regret, it isn't clear that agent-relativity alone is sufficient to explain our especially strong reason to regret the loss of GOOD PAINTING.

Or consider another case: MINOR MEMORIAL/MAJOR MEMORIAL. Suppose MINOR MEMORIAL is a much smaller memorial to a small war and MAJOR MEMORIAL is a much bigger memorial to a bigger war. Suppose zoning restrictions allow only enough space for one memorial. It might be determined that MINOR MEMORIAL needs to go, because MAJOR MEMORIAL commemorates an event of much greater importance to the town and to society at large. MAJOR MEMORIAL, that is, would reflect a much more prominent part of an existing cultural heritage. Even so, it may seem intuitive that the loss of MINOR MEMORIAL is fitting to regret a great deal. It would certainly seem fitting to take a very somber attitude towards the demolition of MINOR MEMORIAL, even if this were immediately accompanied by the creation of MAJOR MEMORIAL.

A respect-centric deontology can explain the asymmetry between OLD/NEW OFFICE versus GOOD/GREAT PAINTING and MAJOR/MINOR MEMORIAL. The loss of historically significant things is the loss of an opportunity to show recognition respect for a cultural heritage. Such a heritage is sustained in large part by the respect shown to things connected with it. A failure to show such respect, as with a failure to fulfill any morally significant imperative, could thus furnish normative reason for regret. Indeed, regret in general seems like a fitting attitude to take towards the failure to live up to a normative standard, at least when 
that standard is itself morally important. And there would be such a reason for regret even if a historically significant thing were less valuable than its possible replacements. For we would still be failing to fulfill an important standard.

Even in cases where the imperative to preserve historically significant things were overridden by other duties, we would still have failed to fulfill a morally significant imperative. Thus we would still have reason for regret in virtue of that failure, and not merely in virtue of the loss of a certain amount of value.

\section{Conclusion}

Of course, preserving historically significant things is not something that everyone is in a position to do. Nor is it something we always ought to do. If a very historic building needs to be cleared away for a critical new hospital, the hospital typically ought to take precedence. There may often be strong reason to regret the loss of historically significant things, and perhaps to preserve them. But there are many other considerations which can outweigh such reasons. Indeed, there are many other duties, virtues and capacities which a society must take seriously.

Now the consequentialist may persist in asking why value maximization should not be the basis for our decisions about when to preserve historically significant things. Perhaps, indeed, the consequentialist has some trouble in accounting for our intuitions about the attitudes we ought to take towards historically significant things. But denying maximizing consequentialism may be a bit of a double-edged sword. For the maximizing consequentialist can challenge the value conservative to come up with a test for when existing sources of value should be preserved and when they should be replaced. What does one do in cases where a replacement would in fact be more valuable than the original, even if the original is quite rare and historically significant? The consequentialist still has an easy reply to such cases: namely, 
replace the original if and only if greater total value would be added by doing so. Clearly, an old building may be very historically significant, but if it's an asbestos-riddled fire trap, replacement may be the only option. Likewise, a country's constitution may embody many important historical traditions, but if it leads to constant strife, it needs to be replaced or at least substantially amended.

It's true that, for the value conservative, just how rare or historically significant something would need to be to warrant preservation is difficult to specify in the abstract. In determining whether something would be worthy of preservation, the value conservative would likely appeal to our intuitive judgments about variations in particular cases, without seeking to provide a hard-and-fast principle that would apply to all cases. Perhaps if this building had not merely been constructed 150 years ago, but had been the site of some important event, such as the signing of a treaty, it would be worth preserving even at the expense of not constructing a nice hotel. But if the building were merely old, perhaps it wouldn't be historically significant enough to preserve at the expense of building a new hotel. The danger for the value conservative is that our intuitive judgments may be inconsistent with each other, or there might be substantial disagreement on preservation decisions even within a given community. Moreover, our intuitive judgments about such cases might simply be false. To test such judgments' truth, the value conservative could not appeal to the maximizing consequentialist's simple criterion: For all things $x$ and $y$, preserve $x$ in lieu of $y$ iff $x$ yields greater total value than $\mathrm{y}$.

Nevertheless, while a consequentialist criterion may be simple to articulate, it may not be simple to apply. To assess how valuable something is, we often have to fall back on intuition. And in any case, it isn't clear that one should adopt a uniform principle for when to preserve historically significant things. Perhaps there should be some variation in preservation decisions between communities and cultures, given different priorities and understandings 
about what constitutes historical significance, and what best puts us in touch with it.

Moreover, the value conservative only needs to provide a rationale for our intuitive judgments that we have especially strong reason to preserve historically significant things. The value conservative does not need to tell us exactly when we should preserve such things. It's far from obvious - indeed it's quite unlikely - that philosophers would be the best guide to preservation decisions, which are often best left to local communities and institutions.

Maybe the lack of a very simple test for when to preserve existing sources of value is a theoretical cost for the value conservative relative to the consequentialist. Value conservatism might then make it harder to decide when existing sources of value ought to be given up in favor of replacements. And this difficulty might well lead us to be cautious about replacing existing sources of value in the first place.

But this could in fact be the right result. Perhaps decisions about whether to replace existing sources of value shouldn't be easy. Perhaps such decisions ought to be hard. And maybe they ought to be hard because society and social individuals have multiple normative standards and duties, not all of which are, or ought to be, easily reconciled.

In any case, the explanatory advantages of value conservatism may well outweigh any costs. The value conservative's resort to non-consequentialist explanation can offer a more plausible moral psychology regarding our treatment of historically significant things. We can thereby make coherent the value conservative's motivations for rejecting the consequentialist approach to such things. 